\title{
Soil-Structure Interaction on the Response of Jacket- Type Offshore Wind Turbine
}

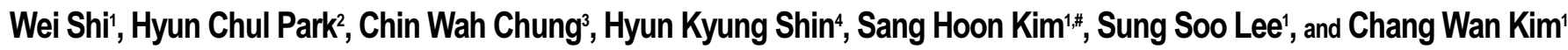 \\ 1 School of Mechanical Engineering, Konkuk University, 120, Neungdong-ro, Gwangjin-gu, Seoul, 143-701, South Korea \\ 2 Department of Mechanical Engineering. Pohang University of Science and Technology, 77, Cheongam-ro, Nam-gu, Pohang-si, Gyeongsangbuk-do, 790-784, South Korea \\ 3 Graduate School of Wind Energy, Pohang University of Science and Technology, 77, Cheongam-ro, Nam-gu, Pohang-si, Gyeongsangbuk-do, 790-784, South Korea \\ 4 School of Naval Architecture \& Ocean Engineering, University of Ulsan, 93, Daehak-ro, Nam-gu, Ulsan, 680-749, South Korea \\ \# Corresponding Author / E-mail: mylily@gmail.com, TEL: +82-2-450-3543, FAX: +82-2-447-5886
}

KEYWORDS: Offshore wind turbine, Jacket type offshore, Soil-Structure interaction, Dynamic analysis

\begin{abstract}
Jacket structures are still at the early stage of their development for use in the offshore wind industry. The aim of this paper is to investigate the effect of the soil-structure interaction on the response of an offshore wind turbine with a jacket-type foundation. For this purpose, two different models of flexible foundation-the p-y model and the p-y model considering pile groups effect-are employed to compare the dynamic responses with the fixed-base model. The modal analysis and the coupled dynamic analysis are carried out under deterministic and stochastic conditions. The influence of the soil-structure interaction on the response of the jacket foundation predicts that the flexible foundation model is necessary to estimate the loads of the offshore wind turbine structure well. It is suggested that during fatigue analysis the pile group effect should be considered for the jacket foundation.
\end{abstract}

\section{NOMENCLATURE}

$P_{d}=$ dynamic soil reaction at depth $h,(\mathrm{~N} / \mathrm{m})$

$P_{s}=$ static soil reaction obtained from the static $p-y$ curve at depth $h,(\mathrm{~N} / \mathrm{m})$

$a_{0}=$ dimensionless frequency $\left(a_{0}=\omega y / V_{s}\right)$

$\omega=$ frequency of loading, $(\mathrm{rad} / \mathrm{s})$

$D=$ pile diameter, $(\mathrm{m})$

$U_{\text {rel }}=$ the relative wind velocity

$H s=$ the significant wave height

$u_{s}=$ the structure velocity

$\mathrm{P}=$ the soil reaction at the same depth for a single pile

$D=$ the average pile diameter from surface to depth $h$

$y=$ lateral pile deflection at depth $h,(\mathrm{~m})$

$V_{s}=$ shear wave velocity of the soil layer, $(\mathrm{m} / \mathrm{s})$

$\alpha, \beta, \kappa$ and $n$ are constants that depend on the soil type

\section{Introduction}

Wind energy has become the most cost-effective of all currently exploited renewable energy sources. ${ }^{1}$ Besides the industrial application success, many researchers have made significant contributions to the wind energy technology. ${ }^{2-5}$ In recent years, offshore wind energy has attracted more attention due to better wind conditions and negligible visual impact compared with onshore wind energy. Although offshore wind energy has experienced rapid development, there is still a growing global demand for wind energy production. ${ }^{6-9}$

Various offshore wind farms have been operated since the 1990s. Up to now, most wind turbines have been installed with monopile or gravity foundations in shallow water depths of $20-30 \mathrm{~m}$. With the aid of technologies from the oil and gas industry, research work is ongoing for greater water depths of 40-100 m, where hydrodynamic transparent designs, such as jacket structures are commonly used.

Jacket structures are commonly used in the offshore oil and gas industry. Many design elements and assessment procedures can be transferred to the design of an offshore jacket wind turbine (OWT). Mostafa and Naggar ${ }^{10}$ undertook a parametric study of the soil-structure interaction on the response of a jacket structure subjected to transient loading due to extreme waves and currents. Elshafey et al. ${ }^{11}$ studied the dynamic response of a scale model of a jacket offshore structure both theoretically and experimentally. Rollins et al. ${ }^{12}$ performed a series of full-scale cyclic lateral load tests on pile groups with various spacings 
to study the effect of pile spacing on the behavior of the pile group. However, the complexity and specialized issues of OWT designs do not allow the direct application of offshore oil and gas industry design principles. An analysis of the wind turbine, including the complete support structure, is necessary for design and analysis. Decoupled or coupled analyses were conducted to study the wind turbine behavior and structural dynamics of the jacket-support structures. ${ }^{13-18}$ However, in these previous studies, the jacket substructures are assumed to be rigidly clamped to the seabed. The analytical method for soil-pile interaction and group effect is well developed and commonly used in the offshore oil and gas industry. Different from other offshore industries in which the wave load and gravity load are most important source of loadings, the modeling of OWT should take into account the coupling of aerodynamics, structural dynamics, hydrodynamics, control, and soil dynamics. Especially, the dynamic interactions play an important role in the dynamic response of an OWT. However, only limited work has been done to consider the soil-pile interaction and pile group effect in the coupled analysis of an OWT.

The aim of this work is to investigate the soil-structure interaction and pile group effect (pile-soil-pile interaction) on the dynamic response of an OWT with a jacket foundation using fully-coupled aerohydro-servo-elastic analysis. In this paper, the $p-y$ curve model is used to simulate the soil resistance to the load for a $5 \mathrm{MW}$ OWT with a jacket substructure sited in $50 \mathrm{~m}$ of water under deterministic and stochastic conditions. Different from the $p-y$ model, the $p-y$ curve model with pile group effect is also employed to account for the pilesoil-pile interaction. The effect of the soil-structure interaction is investigated in the modal analysis, coupled dynamic analysis under the deterministic load case, and the stochastic load case.

Analysis results from a set of sensors located at different parts of the jacket substructure are presented in terms of time series, statistics, and power spectrum density function. Fatigue loads are obtained through the rain flow counting method, and $1 \mathrm{~Hz}$ damage equivalent loads (DEL) are calculated and compared for different models.

\section{Theoretical Background}

OWTs are subjected to various loads from aerodynamic loads due to wind, hydrodynamic loads due to waves and currents, gravity loads, and operational loads. In the case of a fixed-bottom foundation, there is also a resistance force from the soil structure. This section describes the theories used to model the system, including the aerodynamic load, hydrodynamic load, and soil-structure interaction.

\subsection{Aerodynamic Loads}

When the turbine rotor is rotating due to the wind, the rotor shaft experiences a torque, as well as a thrust force. From the blade element theory, the thrust force and torque on the rotor could be calculated as follows: ${ }^{19}$

$$
\begin{gathered}
F_{\text {thrust }}=B \int_{0}^{R} \frac{1}{2} \rho U_{r e l}^{2}\left(C_{l} \cos \varphi+C_{d} \sin \varphi\right) c d r \\
Q=B \int_{0}^{R} \frac{1}{2} \rho U_{r e l}^{2}\left(C_{l} \sin \varphi-C_{d} \cos \varphi\right) c r d r
\end{gathered}
$$

where $B$ is the number of blades, $U_{\text {rel }}$ is the relative wind velocity, $c$ is the airfoil chord length, $r$ is the radius, and $C_{l}$ and $C_{d}$ are the lift and drag coefficients, respectively.

\subsection{Hydrodynamic Loads}

Besides the aerodynamic loads, the hydrodynamic loads play a major role in the dynamics of the OWT.

Several wave spectrum functions are proposed to describe the sea state. The most frequently used spectra for wind-generated seas are the Pierson-Moskowitz $(P M)$ spectrum for a fully developed sea and the JONSWAP spectrum for a developing sea. ${ }^{20}$ The formula for the JONSWAP spectrum is written as follows:

$$
\begin{gathered}
S_{J S}(f)=0.3125 H_{s}^{2} T_{P}\left(\frac{f}{f_{p}}\right)^{-5} \exp \left(-1.25\left(\frac{f}{f_{p}}\right)^{-4}\right)(1-0.287 \ln \gamma) \gamma \exp \left(-0.5\left(\frac{\frac{f}{f_{p}}}{\sigma}\right)^{2}\right) \\
\sigma=0.07 \text { for } f<f_{p}, \sigma=0.09 \text { for } f>f_{p}
\end{gathered}
$$

where $H_{s}$ is the significant wave height, $T_{p}$ is the peak period, $f$ is the frequency, $f_{p}$ is the peak frequency and $\gamma$ is the peakedness parameter.

The time history of the ocean wave is computed from the spectrum model. ${ }^{21}$ Based on a frequency band of width of $\Delta f$, the wave height is derived as:

$$
H_{1}\left(f_{1}\right)=2 \sqrt{2 S_{J W}\left(f_{1}\right) \Delta f}
$$

where $f_{l}$ is the frequency within the band $\Delta f$ and $S_{J W}(f 1)$ is the mean amplitude of the spectral density within this band. The period for this band is:

$$
T_{1}=1 / f_{1}
$$

The frequency band of the spectrum is represented with a heightperiod bin $\left(H_{i}, T_{i}\right)$. A random number generator assigns a random phase $\stackrel{\circ}{a}_{i}$ to this pair to retain the randomness of the time history. If the entire spectrum is divided into $N$ frequency banks with width $\mathrm{f}$, then the wave elevation is obtained from: ${ }^{22}$

$$
\eta(t, x)=\sum_{i=1}^{N} \eta_{i}(t, x)=\sum_{i=1}^{N} \frac{H_{i}}{2} \sin \left(2 \pi f_{i} t-k_{i} x+\varepsilon_{i}\right)
$$

The water particle velocity and acceleration for the irregular wave can be expressed as:

$$
\begin{gathered}
u_{w}(t, x)=\sum_{i=1}^{N} 2 \pi f_{i} \frac{H_{i}}{2} e^{k_{i} z} \sin \left(2 \pi f_{i} t-k_{i} x+\varepsilon_{i}\right) \\
\dot{u}_{w}(t, x)=\sum_{i=1}^{N}\left(2 \pi f_{i}\right)^{2} \frac{H_{i}}{2} e^{k_{i} z} \cos \left(2 \pi f_{i} t+k_{i} x+\varepsilon_{i}\right)
\end{gathered}
$$

The derived water particle velocity and acceleration can be used to calculate the wave force using Morison's equation.

For a slender structure in waves, if the diameter $D$ of the cylinder is small compared with the wavelength $\lambda$, or the diffraction parameter $D / \lambda$ is less than 0.2 , the dynamic forces on the structure can be calculated from the drag and inertia components using the relativemotion Morison's equation (Eq. (9)). ${ }^{23}$ The drag and inertia components are calculated from the water particle kinematics aforementioned. The force per unit length of the member is: 


$$
F_{\text {Morision }}=C_{m} \cdot \frac{1}{4} \pi \rho D^{2} \dot{u}_{w}-\left(C_{m}-1\right) \frac{1}{4} \pi \rho D^{2} \dot{u}_{s}+C_{d} \cdot \frac{1}{2} \rho D\left(u_{w}-u_{s}\right)\left|u_{w}-u_{s}\right|
$$

where $u_{w}$ and $\dot{u}_{w}$ are the water particle velocity and acceleration normal to the member vertical direction, respectively. $u_{s}$ is the structure velocity, and $C_{d}$ and $C_{m}$ are drag and inertia coefficients, respectively.

\subsection{Coupled Dynamic Analysis of Wind Turbine with Jacket Substructure}

Offshore wind turbines are designed and analyzed using comprehensive simulation codes that account for the coupled dynamics of the wind inflow, aerodynamics, elasticity, and controls of the turbine, along with the incident waves, sea current, hydrodynamics, and foundation dynamics of the support structure. ${ }^{24}$ These aero-hydroservo-elastic codes incorporate integrated models for wind-inflow, aerodynamic loads (aero), hydrodynamic loads (hydro), control system (servo) behavior and structural-dynamic (elastic) loads (e.g. gravitational, inertial, centrifugal, and gyroscopic loads) in the time domain in a coupled simulation environment (Fig. 1).

\subsection{Soil-Structure Interaction}

Pile foundations are an essential structural component of jacket-type offshore platforms, and the pile soil interaction is of great concern in structural behavior. Several modeling methods can be used in the analysis to account for the soil-structure interaction effect. Fig. 2 shows diagrams of each of the three foundation models that will be investigated in this study (the rotor-nacelle-assembly (RNA) is not shown).

\subsubsection{Fixed-Base Model}

The fixed base model does not account for the soil properties and assumes the jacket to be rigidly connected to the mudline (Fig. 2 (a)). It is the simplest model to use in simulations because no effort is made to match the dynamic characteristics of the true soil-pile system or even to represent the soil and the pile below the mudline. The model is often used in the preliminary design.

\subsection{2 p-y Model $(p-y)$}

The $p-y$ curve $(p-y)$ model incorporates the soil-pile system's $p-y$ curves into the structural response (Fig. 2 (b)). The piles are modeled up to the actual penetration depth. The soil resistance to the pile movement is modeled using $p-y$ curves, and $t-z$ curves for lateral and axial loading, respectively. Static $p-y$ curves for a single pile in sand can be established from the API guidelines: ${ }^{25}$

$$
p_{u}=\min \left(\begin{array}{c}
\left(C_{1} \times h+C_{2} \times D\right) \times \gamma^{\prime} \times h \\
C_{3} \times D \times \gamma^{\prime} \times h
\end{array}\right)
$$

where $p_{u}$ is the ultimate resistance, $(\mathrm{kN} / \mathrm{m}) ; \gamma^{\prime}$ is the effective soil unit weight, $\left(\mathrm{kN} / \mathrm{m}^{3}\right) ; h$ is the depth, $(\mathrm{m})$; and $D$ is average pile diameter from surface to depth $h,(\mathrm{~m}) . C_{1}, C_{2}$, and $C_{3}$ are coefficients determined from the API guidelines.

The lateral soil resistance-deflection $(p-y)$ relationships for sand are non-linear and may be approximated by the following expression:

$$
P_{s}=A \times p_{u} \times \tanh \left[\frac{\kappa \times h}{A \times p_{u}} y\right]
$$

where $A$ is the factor to account for cyclic or static loading ( $A=0.9$ for cyclic, $A=\left(3.0-0.8^{*}(h / D)\right) \geq 0.9$ for static $), p_{u}$ is the ultimate resistance at depth $h$, and $\kappa$ is the initial modulus of the subgrade reaction determined from the API specifications. In this study, only the lateral soil stiffness characteristics are accounted for; no vertical springs are included, i.e., no $t-z$ curves are considered for the shaft friction and no $Q-z$ curves are considered for the pile tip resistance.

Due to the introduction of nonlinearity, damping and pile-soil interaction during transient loading, the dynamic effects of pile foundations can not be accounted for using static $p-y$ curves. The dynamic $p-y$ curves for a single pile are calculated according to the relationship proposed by EI Naggar and Benley. ${ }^{25}$ It relates the static $p$ $y$ curves, frequency, and apparent velocity $(\omega y)$ as:

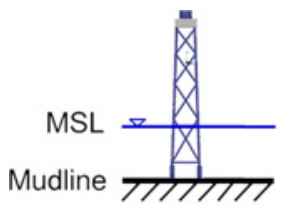

(a) fixed-base model

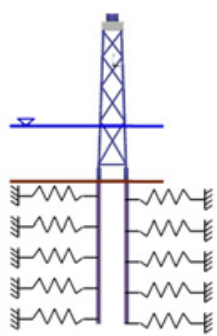

(b) $p-y$ model

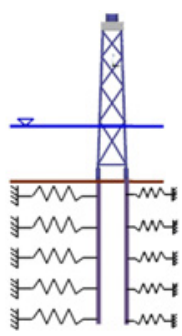

(c) $p-y$ curve with group effect model
Fig. 2 Schematic diagrams of foundation models used in the OWT

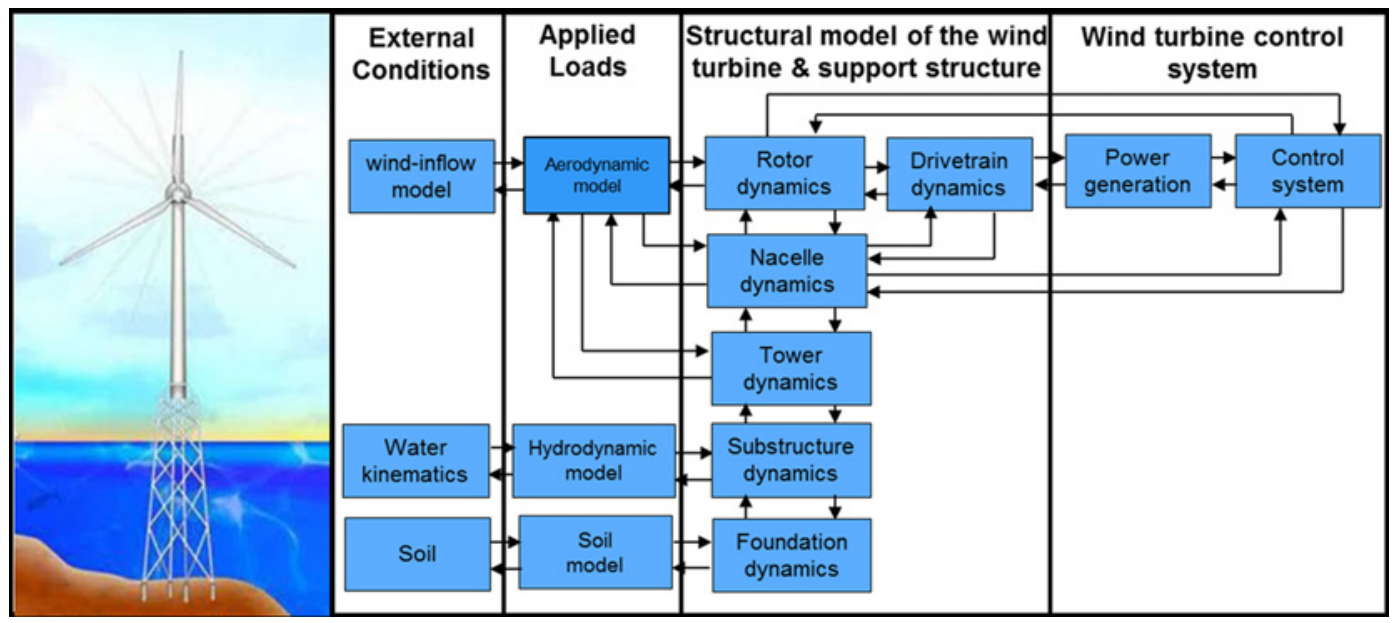

Fig. 1 Aero-Hydro-Servo-Elastic simulation ${ }^{22}$ 


$$
P_{d}=P_{s}\left(\alpha+\beta a_{0}^{2}+\kappa a_{0}\left(\frac{\omega y}{D}\right)^{n}\right)
$$

\subsubsection{P-y Curve with Pile Group Effect Model (p-y with Group Effect)}

Although the $p-y$ method is reliable for evaluating the response of a single pile under the horizontal load, it is questionable if reasonably reliable simple methods could be applied to assess the response of pile groups, e.g. the jacket structure. Generally, for pile spacings of less than six diameters, group effects may have to be evaluated to consider the pilesoil-pile interaction (Fig. 2(c)). Brown et al. ${ }^{7,26}$ introduced the notion of $p$ multipliers to obtain $p-y$ curves for piles in a group with the aim of assessing the pile group behavior from that of the single pile. The dynamic soil reaction at a certain depth for piles in a group, $P_{g}$, is given as:

$$
P_{g}=P_{m} P
$$

where $P_{m}$ is the $p$-multiplier, and $P$ is the soil reaction at the same depth for a single pile. The $p$-multiplier is a function of the pile spacing $(S)$ and the pile diameter $(D)$ (Fig. 3); it can be calculated from the following equation:

First row piles: $P_{m}=0.26 \ln (S / D)+0.5$

Second row piles: $P_{m}=0.25 \ln (S / D)$

Third or higher row piles: $P_{m}=0.60 \ln (S / D)-0.25$

\section{Analysis Model}

\subsection{Wind Turbine Model}

The NREL 5 MW offshore baseline wind turbine $\operatorname{model}^{8}$ is used for the modeling of the wind turbine in our study because it is a good representative of the characteristics of a typical $5 \mathrm{MW}$ OWT being manufactured today. Furthermore, other research teams and international projects (UpWind project, IEA Wind Annex 23 OC3 and IEA Wind Annex 30 OC4) throughout the world have adopted it as a reference model to standardize baseline OWT specifications. The NREL $5 \mathrm{MW}$ model is a conventional upwind, variable speed, collective pitch horizontal axis wind turbine. Table 1 shows the main dimensions and characteristics of the NREL $5 \mathrm{MW}$ wind turbine. More detailed information can be found in Jonkman's definition. ${ }^{27}$

The jacket model adopted in this work was from the IEA Wind

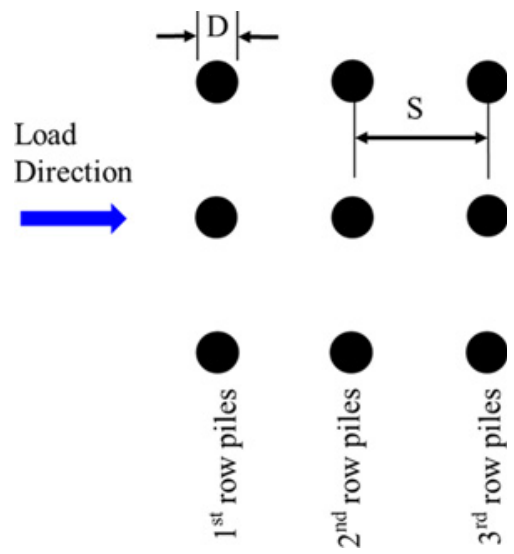

Fig. 3 Load direction, layout of piles in the example pile group
Annex $30 .{ }^{28}$ The water depth was $50 \mathrm{~m}$. The jacket structure consists of four levels of X-braces, mud braces, four central piles, and a transition piece. The piles are flooded, whereas the braces are sealed and contribute significantly to the buoyancy. The jacket is connected to the tower bottom $20 \mathrm{~m}$ above the still water level by a transition piece, which consists of a large volume of reinforced concrete block with a mass of $666 \mathrm{t}$. Table 2 gives the jacket members and pile properties. More detailed system properties can be found in Vorpahl's definition. ${ }^{27}$

\subsection{Soil Model}

Table 3 shows assumed hard soil profile configurations. ${ }^{29}$ The soil parameters are given in terms of the effective soil unit weight $\gamma^{\prime}$ and the angle of internal friction $\varphi$.

\subsection{Foundation Models}

According to the foundation models discussed in Section II, based on the soil and pile properties, the $p-y$ curves for each depth are defined.

In order to take the pile group effect into account, the $p$-multiplier is used. ${ }^{10}$ In this study, each pile is a $2.082 \mathrm{~m}$ outer diameter steel pile with spacing of $12 \mathrm{~m}$ center-to-center in the direction of loading. Therefore, $\mathrm{S} / \mathrm{D}=5.764$, which is close to the group effect marginal value of $6.5^{12}$ The $p$-multiplier for this spacing is determined using Eqs. (15) and (16). For the first row piles: $P_{m}=0.26 \ln 5.764+0.5=0.955$ and the second row piles: $P_{m}=0.25 \ln (5.764)=0.911$.

The $p-y$ curves with group effect for $6 \mathrm{~m}$ below the seabed are compared with the original $p-y$ curve in Fig. 4 . The reduced resistance is visible.

Table 1 Specifications of NREL offshore 5MW wind turbine

\begin{tabular}{cc}
\hline Rated power & $5 \mathrm{MW}$ \\
\hline Rotor orientation & Upwind \\
\hline Control & Variable speed, Collective pitch \\
\hline Rotor/Hub diameter & $126 \mathrm{~m} / 3 \mathrm{~m}$ \\
\hline Hub height & $90 \mathrm{~m}$ above MSL \\
\hline Cut-in, Rated, Cut-out wind speed & $3 \mathrm{~m} / \mathrm{s}, 11.4 \mathrm{~m} / \mathrm{s}, 25 \mathrm{~m} / \mathrm{s}$ \\
\hline Cut-in, Rated rotor speed & $6.9 \mathrm{rpm}, 12.1 \mathrm{rpm}$ \\
\hline Cut-in, Rated generator speed & $670 \mathrm{rpm}, 1173.7 \mathrm{rpm}$ \\
\hline Overhang, Shaft tilt, Precone & $5 \mathrm{~m}, 5^{\circ}, 2.5^{\circ}$ \\
\hline
\end{tabular}

Table 2 Properties of jacket members

\begin{tabular}{cccc}
\hline Set & Component & Diameter & Thickness \\
\hline 1 & x- and mud braces & $0.8 \mathrm{~m}$ & $20 \mathrm{~mm}$ \\
\hline 2 & Leg at lowest level $^{\text {nd }}$ & $1.2 \mathrm{~m}$ & $50 \mathrm{~mm}$ \\
\hline 3 & Leg at $^{\text {nd }}$ to $4^{\text {th }}$ level & $1.2 \mathrm{~m}$ & $35 \mathrm{~mm}$ \\
\hline 4 & Leg crossing transition piece & $1.2 \mathrm{~m}$ & $40 \mathrm{~mm}$ \\
\hline 5 & Pile $(50 \mathrm{~m}-55 \mathrm{~m})$ (not shown) & $2.082 \mathrm{~m}$ & $60 \mathrm{~mm}$ \\
\hline 6 & Pile $(55 \mathrm{~m}-63 \mathrm{~m})$ (not shown) & $2.082 \mathrm{~m}$ & $65 \mathrm{~mm}$ \\
\hline 7 & Pile $(63 \mathrm{~m}-68 \mathrm{~m})$ (not shown) & $2.082 \mathrm{~m}$ & $52 \mathrm{~mm}$ \\
\hline 8 & Pile $(68 \mathrm{~m}-98 \mathrm{~m})$ (not shown) & $2.082 \mathrm{~m}$ & $28 \mathrm{~mm}$ \\
\hline
\end{tabular}

Table 3 Soil conditions

\begin{tabular}{ccc}
\hline Depths $[\mathrm{m}]$ & $\gamma^{\prime}\left[\mathrm{N} / \mathrm{m}^{3}\right]$ & $\Phi\left[{ }^{\circ}\right]$ \\
\hline $0-3$ & 10000 & 38 \\
\hline $3-5$ & 10000 & 35 \\
\hline $5-7$ & 10000 & 38 \\
\hline $7-10$ & 10000 & 38 \\
\hline $10-15$ & 10000 & 42 \\
\hline $15-50$ & 10000 & 42.5 \\
\hline
\end{tabular}




\section{Environment Conditions}

In this study, two typical load cases under the deterministic and stochastic conditions are investigated. Table 4 shows the deterministic load case with constant wind and regular wave with stream function. For the stochastic case in Table 5, the von Karman spectrum for a wind excitation is combined with the Pierson-Moskowitz spectrum to excite the OWT. No misalignment is considered in this work.

\section{Numerical Result TS and Discussion}

Bladed V4.3 software from Germanischer Lloyd Garrad Hassan ${ }^{19}$ was used in this study. Bladed V4.3 accounts for aerodynamic loads based on the constant or turbulent inflow; it also accounts for hydrodynamic loads by first simulating a random sea surface elevation process, and then applying appropriate wave kinematics and inertia and drag force computations using Morison's equation. Added mass of the structures is calculated as the mass of the displaced water volume, which is used for wave load determination on offshore structures. For the structural response computation, Bladed V4.3 employs a combined modal and multi-body dynamics formulation. The structural damping of 0.004775 for blade and that of 0.01 for the support structure are used in the simulation.

There are different numbers of output parameters, which involve the loads and deflection of the blade, drivetrain, generator, tower, and support

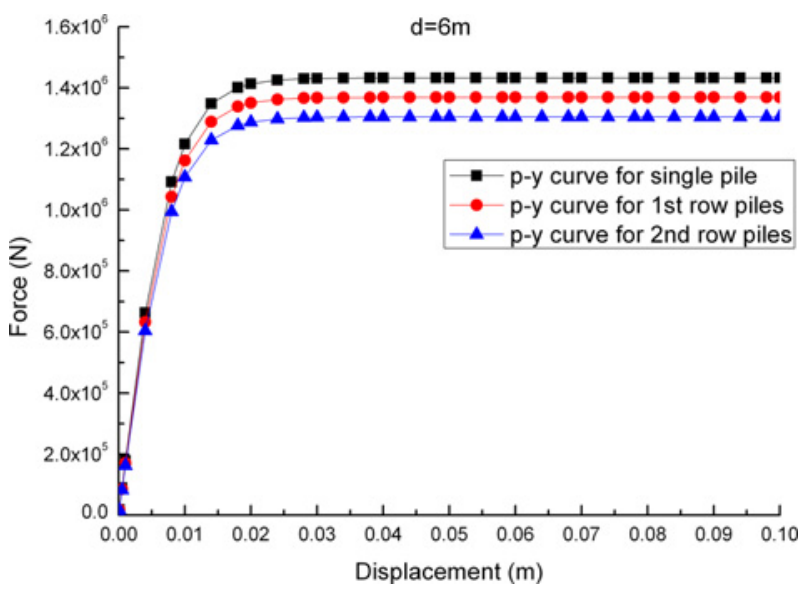

Fig. 4 Sand $p-y$ curves and $p-y$ curves with group effect at depth $6 \mathrm{~m}$

Table 4 Design load case with the deterministic condition

\begin{tabular}{cc}
\hline Degree of freedom & All-platform, tower, drivetrain, blades \\
\hline Wind condition & Steady, uniform, no shear, $\mathrm{V}_{\text {hub }}=8 \mathrm{~m} / \mathrm{s}$ \\
\hline Wave condition & NSS: regular Stream function, $\mathrm{H}=8 \mathrm{~m}, \mathrm{~T}=10 \mathrm{~s}$ \\
\hline Inertial conditions & $\begin{array}{c}\text { Rot Speed }=9 \text { rpm, Azimuth }=0 \text { deg (Blade } 1 \mathrm{up} \text { ), } \\
\text { Blade Pitch }=0 \text { deg }\end{array}$ \\
\hline Turbine status & Operating with the control system enabled \\
\hline
\end{tabular}

NSS: normal sea state ${ }^{31}$ structure. Here, the loads related to jacket foundation are presented.

The modal analysis of the full system is investigated and the natural frequencies related to the support structures are compared in Section A. The loads at typical positions, including the axial and shear forces in leg 2 at the first $K$-joint, the axial and shear forces in the center of brace 59 , the axial force and shear forces of pile 1 at the mudline, are compared between different foundation models (Fig. 5). The time series of the support structures at certain significant locations under the deterministic conditions are compared for different foundation models in Section B. In Section $\mathrm{C}$ the statistics, such as maximum, minimum, and standard deviation, and power spectrum density from the time series at different substructure locations are generated. Fatigue load spectra are obtained through the rain flow counting method which is implemented in GH Bladed; $1 \mathrm{~Hz}$ equivalent loads, which are defined as the peak-to-peak amplitude (i.e. the range) of a sinusoidal load of constant frequency $f$ that would produce the same fatigue damage as the original signal, are calculated with the $S-N$ curve slope, $\mathrm{m}=3$ for welded elements.

\subsection{Modal Analysis}

Table 6 summarizes the natural frequencies related to the support structures for the three foundation models. The fixed-base model is stiffer than the flexible foundation models, and it has less inertia. Hence, natural frequencies for the fixed-base model are seen to be

Table 5 Design load case with the stochastic condition

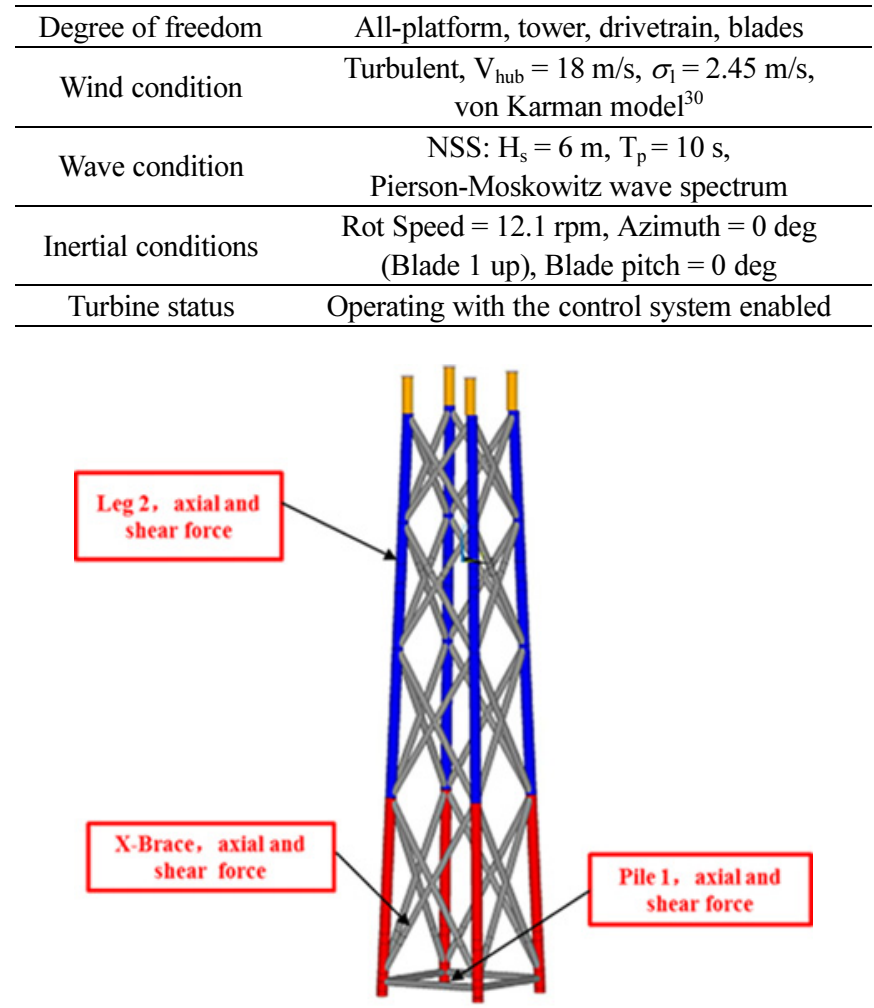

Fig. 5 Illustration of the selected load sensors

Table 6 Natural frequencies of the support structure with different foundation models

\begin{tabular}{ccccccc}
\hline \multicolumn{7}{c}{ Natural frequency $(\mathrm{Hz})$} \\
\hline Model & $1^{\text {st }}$ fore-aft & $1^{\text {st }}$ side-to-side & $2^{\text {nd }}$ fore-aft & $2^{\text {nd }}$ side-to-side & $3^{\text {rd }}$ side-to-side & $1^{\text {st }}$ torsion \\
\hline Fixed-base & 0.3154 & 0.3173 & 1.2265 & 1.3984 & 3.248 & 6.1224 \\
\hline$p-y$ & 0.2772 & 0.2796 & 0.8942 & 1.0249 & 2.6760 & 5.6148 \\
\hline$p-y$ curve with group effect & 0.2771 & 0.2795 & 0.8931 & 1.0233 & 2.6687 & 5.6035 \\
\hline
\end{tabular}


higher than those for the flexible foundation models; this is especially true for the second and third bending modes in both fore-aft and side-toside directions. Compared with the $p-y$ model, all the natural frequencies decrease slightly (less than $0.5 \%$ ) if the pile group effect is considered.

\subsection{Design Load Case for Deterministic Condition}

In this section, the time series of the dynamic response under the constant wind and regular wave conditions are outputted with respect to the local member coordinate system for each member. The member $\mathrm{X}$-axis is always aligned along the member. The member $\mathrm{Z}$-axis is perpendicular to the member $\mathrm{X}$-axis and aligned according to the direction cosines for the member $\mathrm{Z}$-axis.

Fig. 6 gives the axial and shear forces in leg 2 at the first level Kjoint. The fixed-base model underestimated the axial force significantly. A large difference can be found between the rigid model and the flexible model. The peak value for the fixed-base model is $150 \mathrm{kN}$ lower than that of the $p-y$ model and the $p-y$ curve with pile group effect model. However, the difference between the p-y model and the $p-y$ curve with pile group effect model is really small for this load. For shear force, the differences only can be found at the peak point for $p-y$ curve with group effect.

Fig. 7 presents the axial and shear forces in the center of brace 59 . For the axial force (Fig. 7(a)), all the models predict similar response except that the fixed-base model overestimates the shear force in the brace 59; in Fig. 7(b), fixed-base model displays the largest oscillation range and maximum value for shear in the center of brace 59 while $p$ $y$ curve with group effect predicts the smallest maximum peak value.

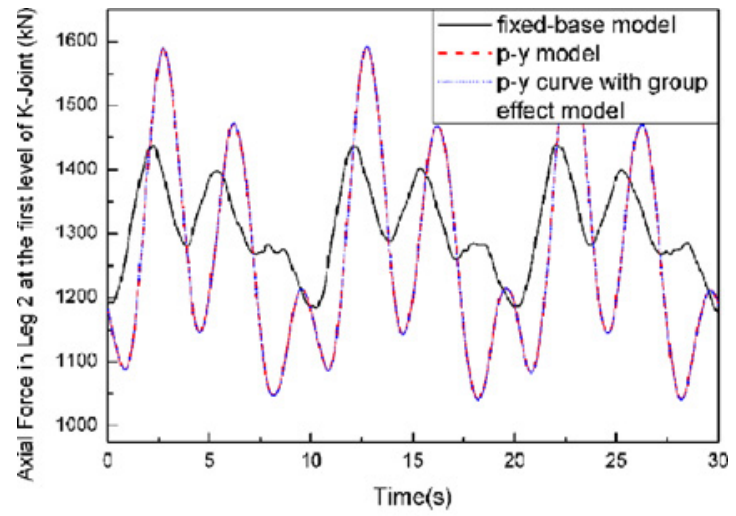

(a)

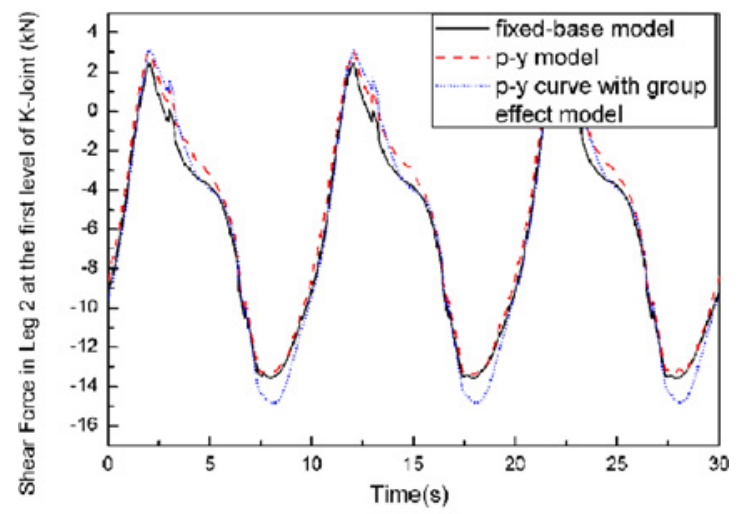

(b)

Fig. 6 Comparison of the force in Leg 2 at the first level of K-joint under deterministic condition for (a) Axial force (b) Shear force

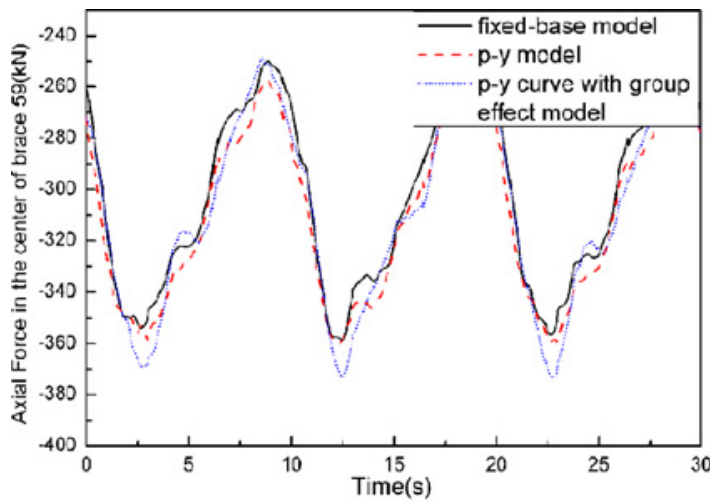

(a)

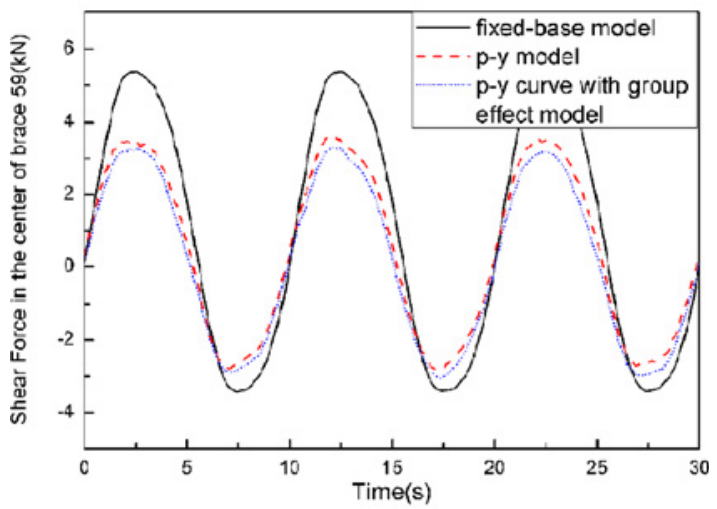

(b)

Fig. 7 Comparison of the force in center of brace 59 under deterministic condition for (a) Axial force (b) Shear force

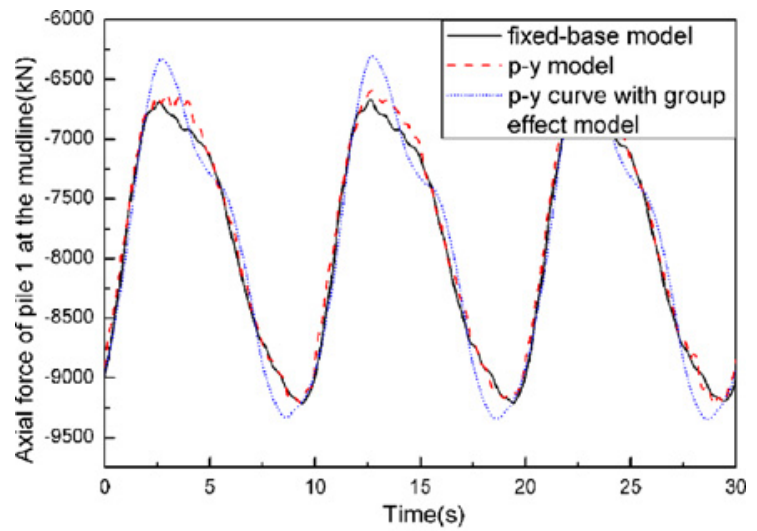

(a)

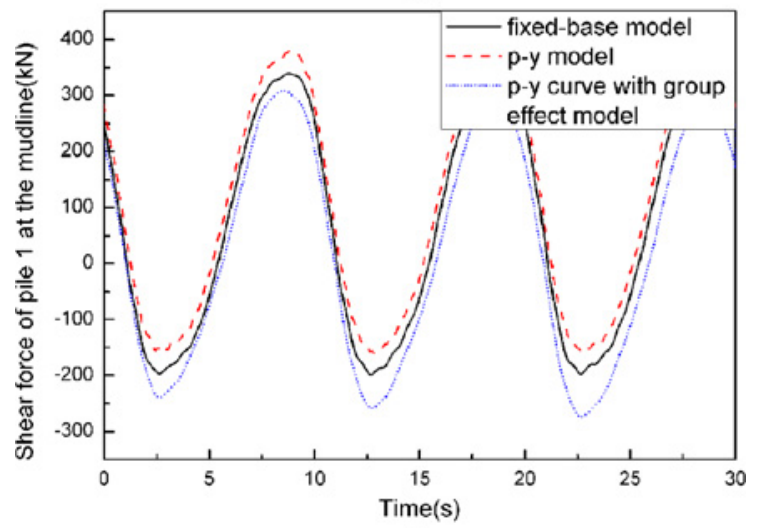

(b)

Fig. 8 Comparison of the force of pile 1 at the mudline under deterministic condition for (a) Axial force (b) Shear force 
Fig. 8 shows the axial and the shear force of pile 1 at the mudline. The $p-y$ curve with group effect model demonstrates the larger value of axial force compared with the fixed-base model and the $p-y$ model. The shear force at the positive peak from the $p-y$ model is $40 \mathrm{kN}$ higher than the fixed-base model and $70 \mathrm{kN}$ higher compared to the $p-y$ curve with the group effect.

\subsection{Design Load Case for Stochastic Condition}

The coupled analysis is performed to obtain the statistical results, the power spectrum density, and the $1 \mathrm{~Hz}$ DEL under the turbulent wind flow and the irregular wave conditions defined in Table 5. The axial and shear force from the typical locations (Fig. 5) are compared for different foundation models.

From Table 7, we can see that the fixed-base model leads to a higher maximum, and standard deviation for the axial force of leg 2 at the first level K-joint. The pile group effect reduces the maximum axial force significantly, and the minimum value is much lower than the other two models. The maximum axial force from the $p-y$ curve with group effect model is about $3 \%$ lower than that of the $p-y$ model. In the case of shear force of leg 2 at the first level K-joint, similar responses are predicted from three models (Table 8 ). Table 4 shows the axial force in the center of brace 59. The pile group has a significantly effect on this axial force. The maximum value is higher than the fixed-base model and the $p-y$ model. There is a different trend compared to the deterministic case. This is because brace 59 (Table 4) is under tension at the maximum axial force with wind speed over rated wind speed, while brace 59 (Fig. $7(a)$ ) is under compression at the maximum axial force with wind speed below rated wind speed in the deterministic case. Since all the members are subjected to compression load most of time, the negative minimum value is more important to the axial force. The fixed-base model underestimates the axial force of brace 59 compared with the other two model because of neglecting the soil-structure interaction. The shear force in the center of brace 59 is quite small compared with other member forces (Table 5). For (Table 6), the fixed-base model underestimates the minimum value of the axial force in pile 1 at the mudline compared with the other two models because of neglecting the soil-structure interaction. Due to the smaller value of the equivalent spring stiffness, the $p-y$ curve with group effect model has smaller minimum value than the $p-y$ model. But larger maximum value from the $p$ - $y$ curve with group effect model results are presented for the shear force in pile 1 at the mudline (Table 7).

The $3600 \mathrm{~s}$ time series data are used to calculate $1 \mathrm{~Hz}$ DEL based on the rain flow counting method to obtain statistically comparable results for the fatigue analysis. The $1 \mathrm{~Hz} \mathrm{DEL}$ is equivalent to $6.312 \times 10^{8}$ cycles in 20 years of a turbine lifetime. The results for different output sensors are given in Tables 7-12. In the case of the axial force in leg 2 (Table 7) and pile 1 (Table 6), the DEL from the fixed-base model have the highest values. The results from the $p-y$ curve with group effect model decrease about $10 \%$ and $3 \%$, respectively, compared with the $p-y$ model. Table 4 shows that the fixed-base model underestimates the DEL axial force in the center of brace 59 compared with the $p-y$ model and the $p-y$ curve with group effect model. The pile group effect has $28 \mathrm{kN}$ higher DEL than the $p$ $y$ model, which is about $12 \%$. For the shear force in center of brace 59 (Table 10), due to their small absolute values, the DEL from the $p-y$ model increases about $75 \%$ than the fixed-base model, and the $p-y$ curve with group effect model increases $23 \%$ more compared with $p$ $y$ model. In Table 6 , the DEL from the $p-y$ model is a $5 \%$ higher value than that of the fixed-base model, while the $p-y$ curve with group effect model gives a $4 \%$ higher DEL than the $p-y$ model.

Figs. 9-11 show the power spectrum density of the axial and shear forces of leg 2 at the first level K-joint, the axial and shear forces in center of brace 59, and the axial and shear forces of pile 1 at the mudline, respectively. In general, the three models produce fairly similar spectra. Most of the energy content is concentrated in the low-

Table 7 Statistics and DELs from stochastic load case for Leg 2 axial force at first K-joint (unit: $\mathrm{kN}$ )

\begin{tabular}{ccccc}
\hline Model & Max & Min & Std.Dev & DEL $(\mathrm{m}=3)$ \\
\hline fixed-base & 2881.2 & -1069.9 & 432.7 & 760.3 \\
\hline$p-y$ & 2804.1 & -1308.3 & 430.0 & 696.5 \\
\hline $\begin{array}{c}p-y \text { curve with } \\
\text { group effect }\end{array}$ & 2708.5 & -507.5 & 392.9 & 626.6 \\
\hline
\end{tabular}

Table 8 Statistics and DELs from stochastic load case for Leg 2 shear force at first K-joint (unit: $\mathrm{kN}$ )

\begin{tabular}{ccccc}
\hline Model & Max & Min & Std.Dev & DEL $(m=3)$ \\
\hline fixed-base & 13.8 & -26.4 & 5.0 & 10.0 \\
\hline$p-y$ & 16.1 & -25.3 & 5.2 & 11.7 \\
\hline $\begin{array}{c}p-y \text { curve with } \\
\text { group effect }\end{array}$ & 16.1 & -26.2 & 5.2 & 10.6 \\
\hline
\end{tabular}

Table 9 Statistics and DELs from stochastic load case for axial force in center of Brace 59 (unit: $\mathrm{kN}$ )

\begin{tabular}{ccccc}
\hline Model & Max & Min & Std.Dev & DEL $(m=3)$ \\
\hline fixed-base & 107.4 & -663.6 & 92.9 & 225.1 \\
\hline$p-y$ & 74.8 & -758.0 & 98.3 & 242.3 \\
\hline $\begin{array}{c}p-y \text { curve with } \\
\text { group effect }\end{array}$ & 111.1 & -755.6 & 104.9 & 270.4 \\
\hline
\end{tabular}

Table 10 Statistics and DELs from stochastic load case shear force in center of Brace 59 (unit: $\mathrm{kN}$ )

\begin{tabular}{ccccc}
\hline Model & Max & Min & Std.Dev & DEL $(m=3)$ \\
\hline fixed-base & 5.4 & -3.2 & 1.3 & 2.0 \\
\hline$p-y$ & 6.4 & -5.7 & 1.6 & 3.5 \\
\hline $\begin{array}{c}p-y \text { curve with } \\
\text { group effect }\end{array}$ & 5.0 & -14.4 & 2.4 & 4.3 \\
\hline
\end{tabular}

Table 11 Statistics and DELs from stochastic load case for axial force for pile 1 at the mudline (unit: $\mathrm{kN}$ )

\begin{tabular}{ccccc}
\hline Model & Max & Min & Std.Dev & DEL $(m=3)$ \\
\hline fixed-base & -5041.7 & -9980.7 & 639.5 & 1267.1 \\
\hline$p-y$ & -4753.6 & -10509.7 & 716.1 & 1254.9 \\
\hline $\begin{array}{c}p-y \text { curve with } \\
\text { group effect }\end{array}$ & -4554.7 & -10273.2 & 688.4 & 1216.8 \\
\hline
\end{tabular}

Table 12 Statistics and DELs from stochastic load case for shear force for pile 1 at the mudline (unit: $\mathrm{kN}$ )

\begin{tabular}{ccccc}
\hline Model & Max & Min & Std.Dev & DEL $(m=3)$ \\
\hline fixed-base & 510.0 & -325.2 & 105.4 & 202.9 \\
\hline$p-y$ & 563.5 & -350.4 & 109.1 & 213.0 \\
\hline $\begin{array}{c}p-y \text { curve with } \\
\text { group effect }\end{array}$ & 578.8 & -294.9 & 108.1 & 221.6 \\
\hline
\end{tabular}




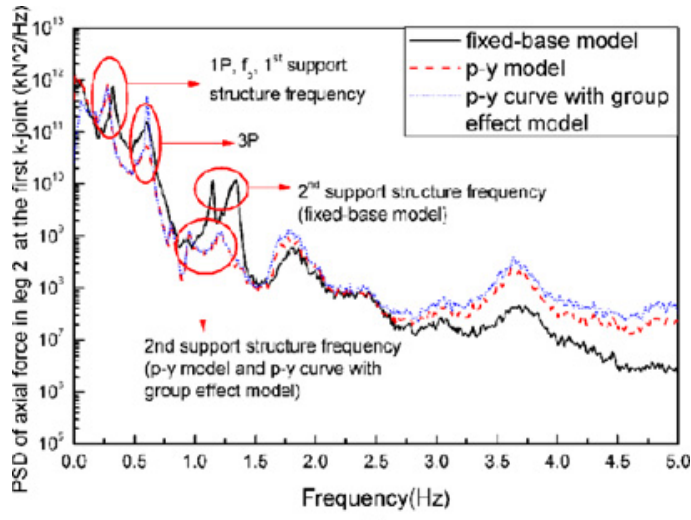

(a)

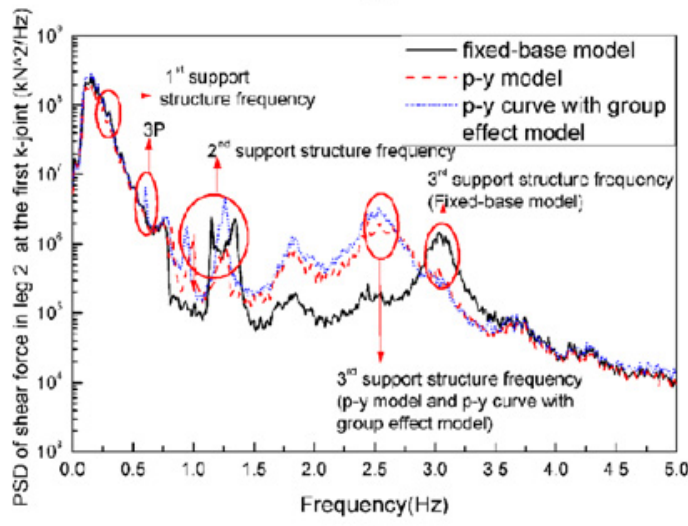

(b)

Fig. 9 Comparison of the PSD of the force in Leg 2 at the first level of K-joint under stochastic condition for (a) Axial force (b) Shear force
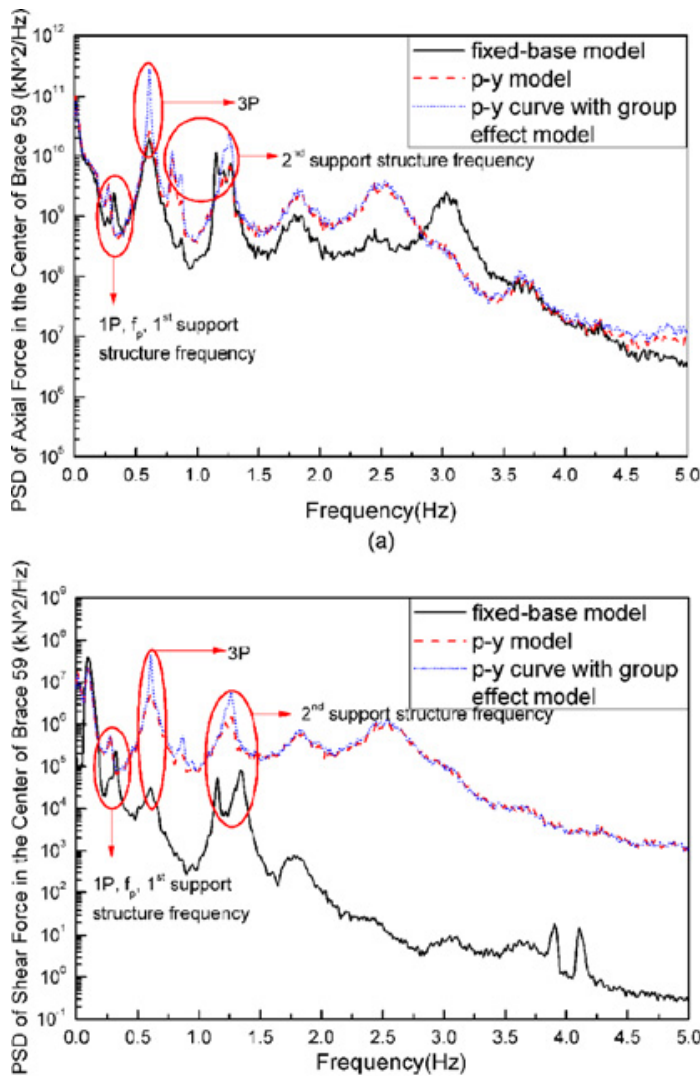

(b)

Fig. 10 Comparison of the PSD of the force in center of brace 59 under stochastic condition for (a) Axial force (b) Shear force frequency range, where the first support structure natural frequency, the peak spectral frequency of the waves $\left(f_{p}=1 / T_{p}\right)$, and the $1 P$ frequency all occur. The 1P frequency refers to the frequency at which the rotor makes a complete revolution. Since the stochastic sea state used in our study has mean wind speeds $(18 \mathrm{~m} / \mathrm{s})$ above the rated wind speed $(11.4 \mathrm{~m} / \mathrm{s})$, the rotor will predominantly be rotating at the rated rotor speed of $12.1 \mathrm{rpm}$, or approximately $0.2 \mathrm{~Hz}$. The flexible foundation models have relatively more energy in this low-frequency range compared with the fixed-base model. The 3P frequency, which refers to the blade passing frequency, is shown clearly in the power spectra of the three models. The fixed-base model shows peaks at first and second support structure frequency slightly to the right of the $p-y$ model and the $p-y$ curve with group effect model. It is the evident from Table 6 that the fixed-base model has higher frequencies than the other two models. The $p-y$ curve with group effect model reveals peaks at the same frequency as the $p-y$ model for all power spectra, but the energy content is slightly higher than the $p-y$ model.

\section{Conclusions}

In this paper, the effect of the soil-structure interaction on the dynamic response of a $5 \mathrm{MW}$ OWT with a jacket foundation is investigated using two flexible foundation models. The $p-y$ model is adopted to consider lateral soil resistance. Because of the pile-soil-pile interaction of jacket piles, the $p$-multiplier is used to take the pile group effect into account. The coupled dynamic responses from two flexible

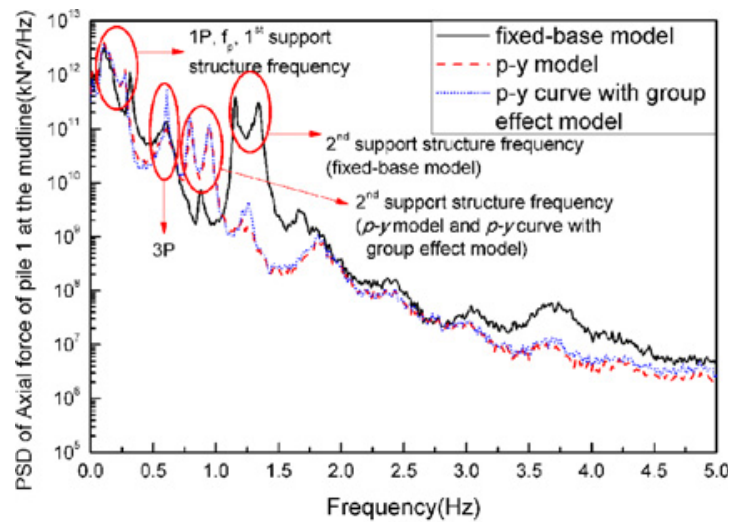

(a)

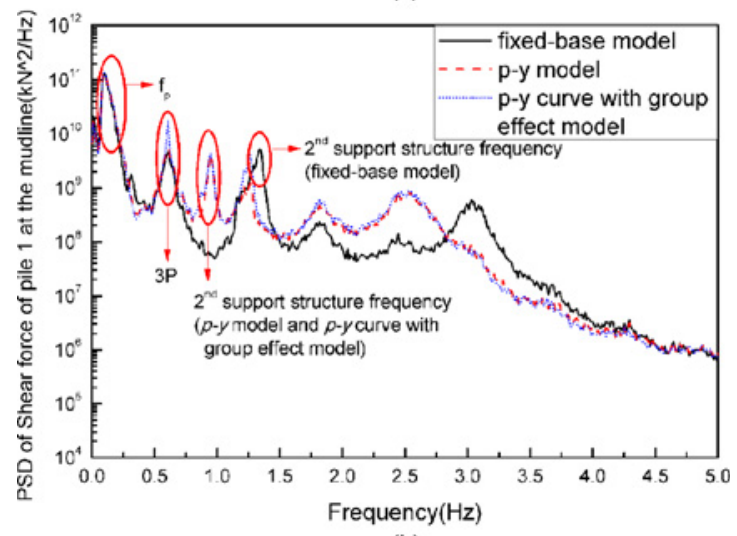

(b)

Fig. 11 Comparison of the PSD of the force of pile 1 at the mudline under stochastic condition for (a) Axial force (b) Shear force 
models are compared with the fixed-base model.

Modal analysis shows that the fixed-base model overestimates the natural frequencies related to the support structure. There is a minor decrease from the $p-y$ curve with group effect model compared with the $p-y$ model.

The dynamic responses of the axial and shear forces of leg 2 at the first level K-joint, the axial and shear forces in the center of brace 59, and the axial and shear force of pile 1 at the mudline under the deterministic condition show that the fixed-base model and $p-y$ curve model underestimate the responses in the leg and pile while overestimate the response in the brace comparing with $p$ - $y$ curve with group effect model. Only a small effect comes from the pile group effect for the deterministic condition.

The fixed-base model leads to higher DELs for the axial force in leg 2 and the axial force in pile 1 than the $p-y$ model and the $p-y$ curve with group effect model, while lower DEL are found for the axial force in the center of brace 59 and the shear force in pile 1. The largest difference between the $p-y$ model and the $p-y$ curve with group effect model occurs for the DEL of the axial force in the center of brace 59.

From this study, it is concluded that soil-structure interaction should be considered in the design and load calculation of an OWT with a jacket-support structure. The pile group effect is more important in the fatigue analysis. In this specific jacket model, a significant effect is also found for S/D of 5.764. The pile group effect should be taken into account in the load calculation for the jacket foundation.

\section{ACKNOWLEDGEMENT}

This research was supported by Defense Acquisition Program Administration and Agency for Defense Development under the contract UD120037CD and also supported by the New \& Renewable Energy of the Korea Institute of Energy Technology Evaluation and Planning (KETEP) grant funded by the Korea Government Ministry of Knowledge and Economy (MKE), South Korea (No. 20124030200110) and also supported by the National Research Foundation of Korea (NRF) funded by the Ministry of Education, Science and Technology (grant number 2012R1A1A2008870 and 2012R1A2A2A04047240).

\section{REFERENCES}

1. BTM Consult, "International Wind Energy Development: World Market Update 2011,” 2012.

2. Ackermann, T. and Söder, L., "Wind Energy Technology and Current Status: A Review," Renewable and Sustainable Energy Reviews, Vol. 4, No. 4, pp. 315-374, 2000.

3. Davenport, A. G., "Past, Present and Future of Wind Engineering," Journal of Wind Engineering and Industrial Aerodynamics, Vol. 90, No. 12, pp. 1371-1380, 2002.

4. Shi, W., Kim, C. W., Chung, C. W., and Park, H. C., "Dynamic Modeling and Analysis of a Wind Turbine Drivetrain using the Torsional Dynamic Model,” Int. J. Precis. Eng. Manuf., Vol. 14, No. 1, pp. 153-159, 2013.
5. Shi, W., Park, H. C., Na, S. K., Song, J. S., Ma, S. J., et al., "Dynamic Analysis of Three-Dimensional Drivetrain System of Wind Turbine," Int. J. Precis. Eng. Manuf., Vol. 15, No. 7, pp. 1351-1357, 2014.

6. Shi, W., Park, H. C., Han, J. H., Na, S. K., and Kim, C. W., “A Study on the Effect of Different Modeling Parameters on the Dynamic Response of a Jacket-Type Offshore Wind Turbine in the Korean Southwest Sea," Renewable Energy, Vol. 58, pp. 50-59, 2013.

7. Hensel, J., Sharma, R. M. S., Baxter, C. D. P., and Hu, S.-L. J., "Development of a Technical Type Factor for Jacket Structures for Offshore Wind Turbines in Rhode Island," Journal of Renewable and Sustainable Energy 4, Vol. 4, No. 6, Paper No. 063120, 2012.

8. Snyder, B. and Kaiser, M. J., "A Comparison of Offshore Wind Power Development in Europe and the U.S.: Patterns and Drivers of Development," Applied Energy, Vol. 86, No. 10, pp. 1845-1856, 2009.

9. Coulling, A. J., Goupee, A. J., Robertson, A. N., Jonkman, J. M., and Dagher, H. J., "Validation of a Fast Semi-Submersible Floating Wind Turbine Numerical Model with Deepcwind Test Data," Journal of Renewable and Sustainable Energy, Vol. 5, No. 2, Paper No. 023116, 2013.

10. Mostafa, Y. E. and El Naggar, M. H., "Response of Fixed Offshore Platforms to Wave and Current Loading Including Soil-Structure Interaction," Soil Dynamics and Earthquake Engineering, Vol. 24, No. 4, pp. 357-368, 2004.

11. Elshafey, A. A., Haddara, M. R., and Marzouk, H., "Dynamic Response of Offshore Jacket Structures under Random Loads," Marine Structures, Vol. 22, No. 3, pp. 504-521, 2009.

12. Rollins, K. M., Olsen, K. G., Jensen, D. H., Garrett, B. H., Olsen, R. J., et al., "Pile Spacing Effects on Lateral Pile Group Behavior: Analysis," Journal of Geotechnical and Geoenvironmental Engineering, Vol. 132, No. 10, pp. 1272-1283, 2006.

13. Dong, W., Moan, T., and Gao, Z., "Long-Term Fatigue Analysis of Multi-Planar Tubular Joints for Jacket-Type Offshore Wind Turbine in Time Domain," Engineering Structures, Vol. 33, No. 6, pp. 20022014, 2011.

14. Fischer, T., Popko, W., Sørensen, J. D., and Kühn, M., "Load Analysis of the Upwind Jacket Reference Support Structure," DEWI, 2010.

15. Gao, Z., Saha, N., Moan, T., and Amdahl, J., "Dynamic Analysis of Offshore Fixed Wind Turbines under Wind and Wave Loads using Alternative Computer Codes," Proc. of the Torque Conference, 2010.

16. Klose, M., Dalhoff, P., and Argyriadis, K., "Integrated Load and Strength Analysis for Offshore Wind Turbines with Jacket Structures," Proc. of the Seventeenth International Offshore and Polar Engineering Conference, pp. 1-6, 2007.

17. Moll, H., Vorpahl, F., and Busmann, H.-G., "Dynamics of Support Structures for Offshore Wind Turbines in Fully-Coupled Simulations-Influence of Water Added Mass on Jacket Mode 
Shapes, Natural Frequencies and Loads," Proc. of the European Wind Energy Conference and Exhibition, 2010.

18. Seidel, M., "Jacket Substructures for the Repower $5 \mathrm{~m}$ Wind Turbine," Proc. of the European Offshore Wind Conference and Exhibition, 2007.

19. Manwell, J. F., McGowan, J. G., and Rogers, A. L., "Wind Energy Explained: Theory, Design and Application,” John Wiley \& Sons, $1^{\text {st }}$ Ed., 2002.

20. Chakrabarti, S. K., "Hydrodynamics of Offshore Structures," WIT Press, 1987.

21. Chakrabarti, S. K., "Handbook of Offshore Engineering," Elsevier, 2005.

22. Faltinsen, O. M., "Sea Loads on Ships and Offshore Structures," Cambridge University Press, 1993.

23. Merz, K. O., Moe, G., and Gudmestad, O. T., "A Review of Hydrodynamic Effects on Bottom-Fixed Offshore Wind Turbines," Proc. of the $28^{\text {th }}$ ASME International Conference on Ocean, Offshore and Arctic Engineering, pp. 927-941, 2009.

24. Jonkman, J. M., "Dynamics Modeling and Loads Analysis of an Offshore Floating Wind Turbine,’ ProQuest, 2007.

25. American Petroleum Institute, "Recommended Practice for Planning, Designing and Constructing Fixed Offshore PlatformsWorking Stress Design,” Thomson Reuters, $21^{\text {st }}$ Ed., 2007.

26. Hesham, E. N. M. and Bentley, K. J., "Dynamic Analysis for Laterally Loaded Piles and Dynamic $p-y$ Curves," Canadian Geotechnical Journal, Vol. 37, No. 6, pp. 1166-1183, 2000.

27. Brown, D. A., Morrison, C., and Reese, L. C., "Lateral Load Behavior of Pile Group in Sand," Journal of Geotechnical Engineering, Vol. 114, No. 11, pp. 1261-1276, 1988.

28. Jonkman, J. M., Butterfield, S., Musial, W., and Scott, G., "Definition of a 5-MW Reference Wind Turbine for Offshore System Development," National Renewable Energy Laboratory Golden, Paper No. NREL/TP-500-38060, 2009.

29. Vorpahl, F., Kaufer, D., and Popko, W., "Description of a Basic Model of the 'Upwind Reference Jacket' for Code Comparison in the OC4 Project under IEA Wind Annex 30," Fraunhofer Institute for Wind Energy and Energy System Technology IWES, 2011.

30. De Vries, W., Vemula, N. K., Passon, P., Fischer, T., Kaufer, D., et al., "Final Report WP4.2: Support Structure Concepts for Deep Water Sites," UpWind D4.2.8, Paper No. 019945, 2011.

31. International Electrotechnical Commission, "Wind Turbines-Part 3: Design Requirements for Offshore Wind Turbines," Paper No. IEC61400-3, 2009. 